\title{
INVESTIGAÇÃO E CONTROLE DE EPIDEMIA DE ESCABIOSE: UMA EXPERIÊNCIA EDUCATIVA EM ALDEIA INDÍGENA
}

\author{
Sonia Maria Lofredo* \\ Cândida Bernadete de Oliveira** \\ Douglas Rodrigues***

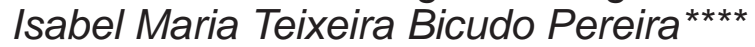

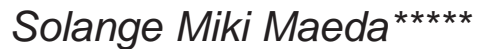

\begin{abstract}
RESUMO: Este trabalho refere-se ao controle de uma epidemia de escabiose em aldeia da tribo Panará, localizada no Xingu, Estado do Mato Grosso, Brasil. Descreve as dificuldades encontradas, decorrentes das diferenças culturais entre os investigadores e a população, o processo de conscientização do problema e a participação de toda comunidade no controle da epidemia de escabiose. Relata estratégias de cunho educativo utilizadas e as dificuldades encontradas para conseguir a adesão da comunidade às ações terapêuticas, essenciais ao controle e eliminação da epidemia. Essas estratégias, alicerçadas no ideário da educação em saúde e de respeito aos conhecimentos, valores e necessidades do grupo, previam a participação da comunidade como elemento essencial à consecução dos objetivos dos profissionais de saúde. Elas determinaram o redirecionamento do plano de ação inicial que, por meio de ações conjuntas dos profissionais de saúde, lideranças locais e população alvo, permitiu investigar e controlar a situação inicialmente encontrada.
\end{abstract}

PALAVRAS-CHAVE: índios, epidemia, escabiose, agente comunitário de saúde, promoção da saúde, educação em saúde.

\footnotetext{
* Enfermeira aluna do curso de pós-graduação latu sensu da Faculdade de Saúde Pública USP.

**Técnica de Enfermagem do Departamento de Saúde da FUNAI

***Médico Coordenador do Projeto Xingu da Unidade de Saúde e Meio Ambiente - UNIFESP

**** Prof. Dra. Departamento de Prática de Saúde Pública da Faculdade de Saúde Pública USP.

*****Médica Aluna de pós-graduação estrito sensu Departamento de Dermatologia UNIFESP
} 


\section{INTRODUÇÃO}

Pesquisas lingüisticas e etno-históricas revelam que os atuais Panará são os últimos descendentes de um grupo conhecido dos cronistas dos séculos 18 e 19, os chamados "Kayapó do Sul", tidos como desaparecidos no início do século. Esse grupo habitava desde o rio Parnaíba em São Paulo até Goiás e Mato Grosso (HELLAS, 1979; SCHWARTZMAN 1988; GIRALDIN, 1994).

Os Panará foram se deslocando para o Norte e chegaram à região do rio Peixoto de Azevedo antes de 1920. Existem relatos de ataques entre grupos Panará e Kayapó. Os índios Kayabi da região de Teles Pires também se reportaram à conflitos com índios que moravam ao Leste, e usavam bordunas (HEELAS, 1979; SCHWARTZMAN, 1988; GIRALDIN, 1994).

Seria somente a partir da abertura da base da Força Aérea Brasileira na serra do Cachimbo, pela expedição Roncador Xingu da Fundação Brasil Central, onde trabalhavam os irmão Villas Boas, que ocorreram os primeiros contatos documentados entre os Panará e a sociedade envolvente. (HEELAS, 1979; SCHWARTZMAN, 1988).

O contato permanente dos Panará com a sociedade começou indiretamente em 1968, quando os Kayapó, que já haviam entrado em contato com os brancos, atacaram os Panará com armas de fogo e queimaram sua aldeia. No contexto da guerra tradicional indígena, foi um grande massacre. (HEELAS, 1979; SCHWARTZMAN, 1988).

Os irmãos Villas Boas, funcionários da Fundação Brasil Central, souberam desse ataque e começaram a montar sua segunda expedição de contato com esses índios, no entanto os Panará iam fugindo e se juntando a outras aldeias mais distantes das frentes de atração preparadas para o contato. Nessa época, haviam 8 aldeias e uma população estimada de até 600 indivíduos (HEELAS, 1979; SCHWARTZMAN, 1988).

Toda a bacia do rio Peixoto Azevedo era tradicionalmente ocupada pelos Panará. Essa era uma área antiga de perambulação, visitando outras aldeias da mesma etnia, caçando, pescando, fazendo a coleta e obtenção de matéria prima para artesanato e fabricação de ferramentas básicas'. Assim construíam uma série de caminhos (HEELAS, 1979; SCHWARTZMAN, 1988; GIRALDIN, 1994).

Com os topógrafos abrindo o traçado da estrada Cuiabá - Santarém, os Panará foram sendo acometidos de doenças decorrentes dos contatos esporádicos com os vírus 
dos trabalhadores da frente de obras. Muitos iam morrendo, outros fugiam pelo mato, as diversas aldeias, que existiam, se uniram numa única até que, em 1972, uma epidemia, provavelmente de gripe, dizimou a população. Foi a primeira incidência em grande escala de doença até então desconhecida pelos Panará, que chamam esse período de "O tempo em que todo mundo morreu" (SCHWARTZMAN, 1988; HEELAS, 1979).

Em 1973 foram contatados pelos irmãos Villas Boas por meio da FUNAI. Nesse mesmo ano, a estrada foi aberta e os índios ficaram fascinados com as máquinas, muitos trabalhadores, a estrada e o trânsito. Chegaram a construir uma pequena aldeia quase à beira da estrada mas a doença se espalhava e se agravaram os conflitos internos no grupo porque, como costumam atribuir a causa das doenças e as mortes a feitiços, passaram a acusar e matar os feiticeiros de sua aldeia. (SCHWARTZMAN, 1988; HEELAS, 1979).

Com a chegada do exército, apesar do discurso de proteção, veio álcool e índias foram prostituídas

Orlando Villas Boas chegou a alertar as autoridades de que, se uma reserva indígena não fosse demarcada de imediato, com o desenvolvimento de uma política positiva de proteção, os Panará seriam extintos (ARNT, 1998; ISA, 1996; DAVIS, 1977).

Essa reserva não foi criada e, em 1975, os Panará foram transferidos para o Parque Indígena do Xingu. Eram 79 sobreviventes. Os Panará chegaram ao Xingu famintos, anêmicos, com malária, infestados de parasitas e sem nenhuma grávida (BARUSI, 1994; SCHWARTZMAN, 1988; MARCOPITO, 1979).

A transferência para o Xingu resultou também em tensões sociais de difícil resolução. Antes do contato, os Panará não mantinham relações pacíficas com nenhum outro grupo. Fisicamente debilitados, desorganizados socialmente, vulneráveis, inclusive por motivos demográficos, eram poucos e possuíam mais mulheres do que homens (BARUZZI, 1994; SCHWARTZMAN, 1988).

Ao chegar ao Xingu foram morar com os Kayabi e algumas mulheres morreram, acredita-se que tenha sido por envenenamento involuntário causado por cianureto presente na mandioca brava pois os Panará não conheciam esse tipo de mandioca. Esse alimento é tradicionalmente usado pelos Xinguanos em mingaus e beiju. Os Kayabi não tinham suprimento suficiente de alimentos para os Panará. Então as autoridades do Parque resolveram transferí-los para a aldeia de seus antigos inimigos, os Kayapó. Embora houvesse 
Investigação e controle de epidemia de escabiose: uma experiência educativa em aldeia indígena

mais comida nessa aldeia, a situação foi extremamente opressiva e humilhante já que os Kayapó eram seus inimigos tradicionais. Vários de seus familiares haviam sido mortos pelos Kayapó que conheceram as armas de fogo antes deles (BARUZZI, 1994; SCHWARTZMAN, 1988).

Depois da mudança, os Panará continuavam doentes. Os Kayapó queriam suas mulheres e proibiam os Panará de praticar seus rituais. Após difícil negociação com os Kayapó, os Panará se retiraram da aldeia deixando para traz mulheres e crianças (GIRALDIN, 1994; SCHWARTZMAN, 1988; HEELAS, 1979)

A sensação de derrota e a humilhação era tal que se portavam como "cadáveres animados", meditando por horas a fio. Passaram um mês no Posto Diauarum fazendo tratamento médico com a equipe da Escola Paulista de Medicina (MARCOPITO, 1979).

Do posto indígena Diauarum, os Panará foram para a aldeia dos Suya no rio Suia Missu. Com melhores condições de saúde e numa situação menos opressiva, começaram a surgir novas lideranças e aos poucos os rituais foram sendo retomados. Nessa época a população Panará estava reduzida a 67 índios (ARNT,1998; BARUZZI, 1994; SCHWARTZMAN, 1988).

Mudaram-se sete vezes até chegar à aldeia Panará do rio Arraias no Parque Indígena do Xingu, localizada no Estado do Mato Grosso onde esse trabalho foi realizado.

Em novembro de 1991, os Panará sobrevoaram suas antigas terras na região de Peixoto de Azevedo e puderam constatar que ainda estava preservado um trecho de seu tradicional território próximo à serra do Cachimbo e a cabeceira do rio Iriri. Em agosto de 1994, resolveram reivindicar em juízo uma indenização por perdas e danos causados por sua transferência para o Xingu. Ao mesmo tempo iniciaram o processo de reocupação desta parcela de território. (ARNT; 1998; ISA, 1996). Retornar ao território de origem significava para eles recuperar uma altivez que havia sido prejudicada pelos últimos vinte anos (SCHWARTZMAN 1988).

Na época em que esse trabalho foi realizado, a população da aldeia Panará era de 158 pessoas que se dividiam em sete casas. Tinham ultrapassado o processo de declínio de sua população.

A importância desta descrição está no sentimento dominante dessa população que tornou a crescer, recuperando a auto estima e o culto a seus mitos. Esse sentimento de 
Saúde e Sociedade 10(1):65-86, 2001

resgate foi aumentado pelo vôo de reconhecimento de sua antiga área e reivindicação de suas terras. Esse ânimo, colaborou para os Panará "espantarem o espírito da sarna" com suas rezas, ervas, tudo para se curar. Após adquirir vários outros valores em sua permanência no Parque Indígena do Xingu, estavam abertos à nossa proposta de tratamento.

Este trabalho relata a investigação e tratamento de uma epidemia de escabiose ocorrida em fevereiro de 1994 na aldeia onde habitavam os índios Panará, na região centrooeste do Parque Indígena do Xingu, como parte das ações desenvolvidas pelo projeto Xingu da Unidade de Saúde e Meio Ambiente da Universidade Federal de São Paulo (UNIFESP) em parceria com a FUNAI e Fundação Mata Virgem.

\section{CARACTERÍSTICAS DA DOENÇA}

"Sabemos que os problemas de saúde de nossa população apresentam maior intensidade nos grupos social, econômica e culturalmente mais desassistidos." (MENDES, 1990 p 11). "Quando esses problemas são associados às doenças infecciosas freqüentes e enfermidades parasitárias, eles agravam o quadro de saúde desfavorável da população brasileira." (MENDES, 1990 p12). "As doenças ditas parasitárias ocupam sempre posição de pouco destaque nas estatísticas européias e americanas" (SILVA,1985 p135). Isso acontece por que essas doenças, apesar de interferir na qualidade de vida, não são letais.

A escabiose ou sarna é uma ectoparasitose contagiosa, benigna, produzida pelo Sarcoptes scabiei var. hominis, que deposita seus ovos na pele do homem. Sua principal manifestação é o prurido, em geral bastante severo, que ocorre com maior intensidade à noite, não sendo determinado somente pelo deslocamento da fêmea, mas também devido a uma sensibilização do hospedeiro às substâncias excretadas pelo parasito. A distribuição é muito característica, afetando principalmente os espaços interdigitais, axilas, cintura, nádegas, mamas, prepúcio, escroto, face e pés. Devido ao prurido, costumam ocorrer lesões secundárias com escoriações e piodermite como impetigo, foliculite e furúnculo. (PASSARO, 1991; PESSÔA,1974; SAMPAIO, 1974)

Alguns autores afirmam que a escabiose tem natureza cíclica, sendo quinze anos epidêmicos, seguidos de outros quinze de intervalo, considerando o final de uma e início de outra (ÑIGUEZ ET AL., 1988; RICKEY ET AL., 1986).

O conceito de variação cíclica sugere alterações periódicas no estado imunológico da população, no entanto essa característica regular é discutível e o período arbitrado em 
Investigação e controle de epidemia de escabiose: uma experiência educativa em aldeia indígena

trinta anos pode representar uma simplificação da compreensão da epidemiologia da escabiose.(ORKIN, 1971)

"As zoodermatoses sempre ocuparam posição de destaque, como grupo de dermatoses mais freqüentes no Estado do Pará e, por extensão, na Amazônia Legal (onde está localizado o Parque Indígena do Xingu). Em Belém do Pará, houve uma aumento dos casos de escabiose referentes ao decênio 1970-1979, atingindo o máximo no triênio 19751977" (SILVA et al, 1985 p 136).

A escabiose é transmitida por contato pessoal, sem preferência por idade, sexo ou raça. Este contágio pode se dar por via sexual ou pelo contato íntimo. Após a contaminação, o indivíduo pode disseminar o parasita junto às pessoas com quem convive. (ÑIGUEZ ET AL, 1988; SUÁREZ, 1982; SAMPAIO, 1974). A superlotação dos domicílios e a utilização do mesmo leito e de pertences íntimos são fatores importantes no ciclo da transmissibilidade. (ALVARES ET AL, 1991; PASSARO,1991; GULATI et al, 1977; BLUMENTHAL et al, 1976).

"O contato prolongado com um enfermo de sarna é suficiente para que ocorra a contaminação mas o parasito morre rapidamente quando se separa da epiderme humana." (SUÁREZ, 1982 p 681)

\section{CARACTERÍSTICAS DA ETNIA}

Os Panará são índios da família lingüistica Jê setentrional, nômades, com uma sociedade matriarcal e monogâmica (HELLAS, 1979). Com a redução de territórios, se sedentarizaram.

Descendem provavelmente dos Kayapó do Sul. Também chamados de Kren-Akrore, krenakore ou krenakarore, denominações dadas por seus inimigos, os Kayapó, referindose ao corte de cabelo tradicional dessa etnia. Também foram chamados de índios gigantes. A auto denominação Panará significa "gente" (GIRALDIN, 1994; HELLAS, 1979).

Na região de Peixoto de Azevedo, onde habitam os Panará atualmente, os rios são mais estreitos do que os do Xingu. Antigamente eles esperavam as épocas mais secas para atravessá-los ou faziam a travessia com o auxílio de toras de madeira. Pescavam com timbó e arco e flecha embora a base proteíca mais importante de sua alimentação seja a caça (SCHWARTZMAN, 1988; HELLAS, 1979). 
As qualidades da carne e dos animais de caça tem significados míticos associados a doença, saúde, feitiçaria, música, danças e rituais. Alimentam-se da maioria dos mamíferos embora nem todos comam todas as partes de todos os animais devido a alguns tabus. Caçam coletivamente durante semanas para festas ritualísticas importantes, sempre com o objetivo de matar animais específicos como jabuti, anta, macaco, tatu ou onça, espécies mais valorizadas e descritas como "gordurosas" talvez pelo alto valor energético. Também caçam individualmente ou em pequenos grupos em qualquer época do ano durante horas ou até o dia todo (SCHWARTZMAN,1988; HELLAS, 1979).

A plantação para os Panará é tradicionalmente muito importante o que os diferencia de outros grupos da etnia Jê. Suas roças são as maiores e mais produtivas, mesmo no Xingu onde alegam que a terra é vermelha e pior que a terra preta de suas antigas terras (SCHWARTZMAN,1988).

As roças são circulares obedecendo sempre a uma ordem única. Certas plantas são plantadas na periferia da roça, outras no centro, algumas atravessam a roça em linha reta pelo diâmetro e tudo tem uma explicação. Cultivam mandioca, cará, banana, milho, amendoim, batata doce, abóbora, melancia, cana de açúcar e o pequi introduzido recentemente. Como os diferentes vegetais ficam prontos para colheita em diferentes estações do ano, os índios sempre tem algum produto da terra para comer (SCHWARTZMAN,1988).

Assim como na caça, o trabalho de roçar pode ser feito individual ou coletivamente. Embora cada família possua a sua própria roça, geralmente trabalham em mutirão na preparação até o momento do plantio. Então iniciam a preparação de outra roça. A colheita é sempre feito pelas mulheres (SCHWARTZMAN,1988).

Completam sua economia com a extração do mel, castanha do Pará, guaraná, açaí, cacau, cupuaçu, mamão bravo, caju e, atualmente, pequi que adquiriram no Xingu.

Embora em certas épocas do ano pratiquem o nomadismo em seus domínios, possuem aldeia definitiva, assim como várias plantações de caráter definitivo (SCHWARTZMAN,1988; HELLAS, 1979).

No contexto tradicional, os Panará se dividem em 4 clãs nomeados segundo os pontos cardeais. Esses clãs se distribuem no círculo da aldeia conforme o caminho do Sol. As diferentes aldeias apresentam essa mesma configuração. O seu formato circular é uma 
representação da totalidade do universo social do grupo. Grande parte da vida diária da aldeia está centrada na família nuclear. Os grupos domésticos e os clãs ganham importância nas ocasiões de rituais e festas (SCHWARTZMAN,1988; HELLAS, 1979).

Pela tradição, no centro da aldeia havia duas "casas dos homens". Acreditamos que devido a queda populacional hoje existe apenas uma no centro da aldeia. Nesse local ocorrem reuniões importantes, com discursos sobre o preparo de roças, caçadas, grandes festas e tudo o que diz respeito ao grupo (SCHWARTZMAN,1988; HELLAS, 1979).

A segunda "casa dos homens", que ficava no centro da aldeia, servia aos meninos que, residiam ali após completarem 13 anos até estabelecerem vínculos mais estáveis com a mulher com quem fossem se casar. Geralmente reina uma tolerância sexual informal embora os casamentos sejam monogâmicos em sua maioria (SCHWARTZMAN,1988; HELLAS, 1979).

Verifica-se atualmente que alguns membros do grupo vivem uma união poligâmica, observando-se que esta prática pode estar sendo utilizada como estratégia para ampliar a população face ao maior número de mulheres com relação aos homens (BARUZZI, 1994).

Ser transferidos para o Parque Indígena do Xingu, sob o ponto de vista deles, significou estar numa terra alheia e pobre pois, para os índios em geral, a ordem social cosmológica e mítica depende de suas florestas, rios e animais (SCHWARTZMAN, 1988; HELLAS, 1979).

Tendo suas formas tradicionais de manejo e uso de recursos naturais modificados e restritos pela mudança decorrente da transferência, os Panará aprenderam a conviver com outros povos, assimilando muito de sua cultura. Entre outras coisas, aprenderam a pescar com linha, usar panelas, fazer canoas, processar a mandioca brava, usar ferramentas de aço e armas de fogo (SCHWARTZMAN, 1988).

Os índios xinguanos se locomovem em canoas, se alimentam basicamente de peixes, mandioca e da fruta do pequi. A caça foi introduzida no Parque Indígena do Xingu pelos povos levados para lá com a criação do Parque.

Mesmo tendo encontrado condições de sobrevivência no Parque Indígena do Xingu, o grupo nunca se adaptou a essa nova terra, expressando a necessidade do retorno para as entidades ligadas a eles. 
Saúde e Sociedade 10(1):65-86, 2001

Em 1995, os Panará mudaram do Parque Indígena do Xingu para uma parte ainda preservada de suas antigas terras, fundaram a aldeia "Naycepotire" nas cabeceiras do rio Iriri. Seu atual território se localiza entre os municípios de Guarantã do Norte e Altamira, nos estados de Mato Grosso e Pará.

Após cinco anos de esforços conseguiram, em novembro de 1996, que o Ministério da Justiça decretasse a posse permanente de 495 mil hectares de terra que correspondem a quinta parte dos 2,5 milhões de hectares que possuíam antigamente (ARNT, 1998; ISA,1996).

Vivendo com maior segurança em seu próprio ambiente, os Panará ficaram mais estimulados a cuidar da aldeia, fazer festas e voltaram a ter alimentos que não encontravam no Parque Indígena do Xingu. No entanto, ainda sofrem com constantes epidemias de malária e têm dificuldade em obter assistência à saúde.

\section{AGENTES INDÍGENAS DE SAÚDE}

Desde o início da década de oitenta, os médicos, enfermeiros e auxiliares de enfermagem que prestavam atendimento esporádico nos postos indígenas, passaram a contar com a ajuda de índios voluntários, que além de ajudar na comunicação, colaboravam em serviços gerais como buscar água e limpar o local onde era prestado o atendimento.(MS; FNS; CSI, 1996)

Sem poder contar permanentemente com profissionais de saúde, a população indígena, que normalmente procura o pajé e os erveiros, passou a recorrer também a esses índios, como pessoas aptas a lhes prestar assistência nos momentos de dificuldade com doenças introduzidas pelo contato com a civilização dos brancos. Devido essa demanda, os índios, que auxiliavam os profissionais de saúde, passaram a solicitar uma orientação mais específica (MS; FNS; CSI, 1996).

Embora estivesse clara a necessidade de maior orientação, não havia uma política nacional para a formação desses voluntários, que passaram a ser chamados de "agentes indígenas de saúde". Assim sendo, sua formação se deu de forma diferente nas diversas regiões do Parque (MS; FNS; CSI, 1996).

Apoiados pela Fundação Mata Virgem e em parceria com a FUNAI, a Universidade Federal de São Paulo (UNIFESP) implantou um projeto, em que os profissionais de saúde 
Investigação e controle de epidemia de escabiose: uma experiência educativa em aldeia indígena

residiam na área central do Parque Indígena do Xingu, formando e supervisionando esses agentes de saúde. Com esse trabalho e, apesar de algumas limitações (devido principalmente à diferenças culturais), os agentes indígenas de saúde vem sendo capacitados para desenvolver atividades como educação em saúde, diagnóstico e tratamento nas doenças que mais afetam as suas comunidades.

Há que se observar que, mesmo prestando um serviço fundamental, os agentes indígenas de saúde, não podem suprir a necessidade dos profissionais de saúde em sua reserva indígena, devem agir como um elo de ligação entre a sociedade indígena e o sistema oficial de saúde (MS; FNS; CSI, 1996).

O Instituto Sócio Ambiental, em parceria com outros órgãos (Ministério da Educação, Fundação Rain Forest da Noruega, Secretaria de Estado de Educação do Mato Grosso, Funai, Fundação Ford e Abrinq) mantém desde 1994 um projeto de formação de professores no Parque Indígena do Xingu que se estendeu às terras indígenas Panará.

Segundo a coordenadora do projeto, durante esses cursos de formação de professores, os agentes indígenas de educação aprendem também formas de transmissão, sintomas e prevenção de doenças comuns em áreas indígenas.

Com assessoria de especialistas, os agentes indígenas de educação estão elaborando um livro de saúde (em língua indígena e em língua portuguesa) com o material desenvolvido em suas aulas. Será um livro didático que facilitará seu trabalho junto ao agente indígena de saúde na educação para a saúde, partindo de cuidados básicos de higiene e de informações que ajudam a comunidade a prevenir doenças.

Baseado nas diretrizes da Segunda Conferência Nacional de Saúde para os povos indígenas, foi elaborado um projeto de lei (Lei Arouca $n^{\circ}$. 9836) evidenciando os principais aspectos a serem considerados numa política de saúde. Propõe a criação de um subsistema para os povos indígenas vinculado ao SUS, tendo por base os distritos sanitários especiais indígenas (DSEl's) com autonomia administrativa e financeira, tendo na esfera federal a responsabilidade pela gestão e execução dos serviços de saúde (LIEBGOTT, 1999).

Recentes deliberações do poder executivo (medida provisória $\mathrm{n}^{\circ}$.1911-8, Decreto $n^{\circ}$.3.156/99 e Portaria $n^{\circ}$.1.163/99) dão à FUNASA a função gestora, contrariando o que foi reivindicado na Segunda Conferência Nacional de Saúde para os povos indígenas. Nesse caso, a execução é estabelecida por meio de convênios com terceiros, podendo ser ONG's, organizações indígenas, estados e municípios (LIEBGOTT, 1999). 
Saúde e Sociedade 10(1):65-86, 2001

Segundo informações do gestor de saúde da FUNASA (Fundação Nacional de Saúde), atualmente a área Panará pertence ao DSI do município de Colíder que é o responsável pelo controle sanitário, controle das endemias e pelo treinamento dos agentes comunitários de saúde, enquanto que uma parceria da FUNASA com a prefeitura do município de Colíder fica responsável pelos medicamentos, atendimento de saúde nas aldeias, hospitais de base e Casa do Índio, mantendo um auxiliar de enfermagem na aldeia.

O nível de compreensão dos índios varia muito em decorrência do tempo e tipo de contato. Os Panará tem muita dificuldade em entender o português e, embora a formação do conselho distrital seja paritário (50\% índios, 50\% organismos governamentais, ONGs e Universidade), eles pouco debatem e sua participação no conselho é pequena, ficando a responsabilidade pelas ações de saúde a cargo dos prestadores de serviço.

Mesmo antes da mudança dos Panará do Xingu para a aldeia nova, Naycepotire, eles viam a necessidade de ter um profissional de saúde morando na aldeia. Esse modelo muitas vezes se mostrou frágil devido ao pouco preparo e a falta treinamento dos profissionais contratados. O trabalho do auxiliar de enfermagem se mostrou desvinculado do agente indígena de saúde que muitas vezes se sentia desestimulado, deixando de participar das ações de saúde em sua aldeia.

De acordo com a resolução $n^{0} 305$ do Conselho Nacional de Saúde, entre os objetivos da III Conferência Nacional de Saúde está a necessidade de avaliação do processo de organização dos serviços de atenção à saúde indígena na consolidação do Sistema Único de Saúde (LIEBGOTT, 1999).

\section{APRESENTAÇÃO DO PROBLEMA}

Em fevereiro de 1994, houve um aumento abrupto nos casos de escabiose na aldeia Panará localizada ao norte do Parque Indígena do Xingu que foi confirmada por exames clínicos feitos em todos os índios.

Toda a população estava parasitada como mostra a tabela a seguir: 
Investigação e controle de epidemia de escabiose: uma experiência educativa em aldeia indígena

Prevalência de casos de escabiose e escabiose com piodermite por faixa etária na população indígena Panará (MT,1994)

\begin{tabular}{l|l|l|l|l|ll}
\hline \multirow{2}{*}{ faixa etária } & \multicolumn{2}{|c|}{ escabiose } & \multicolumn{2}{c}{ escabiose com piodermite } & \multicolumn{2}{c}{ total } \\
\cline { 2 - 6 } & $\mathrm{n}^{0}$ & $\%$ & $\mathrm{n}^{0}$ & $\%$ & $\mathrm{n}^{0}$ & $\%$ \\
\hline & 2 & 50,0 & 2 & 50,0 & 4 & 100,0 \\
$<1$ & 19 & 63,3 & 11 & 36,7 & 30 & 100,0 \\
$1-4$ & 73 & 98,6 & 1 & 1,6 & 74 & 100,0 \\
$5-14$ & 60 & 100,0 & - & - & 60 & 100,0 \\
$>15$ & 154 & 91,7 & 14 & 8.3 & $168^{*}$ & 100,0 \\
\hline total & & & & & & \\
\hline
\end{tabular}

*Número total de indivídduos da aldeia; todos foram acometidos pela escabiose.

O conhecimento dos costumes daquela população permitiu a identificação dos motivos e causas da epidemia.

Após o contato com os brancos, os Panará passaram por mudanças decorrentes da assimilação de hábitos de outras culturas. Esses índios, que andavam nus e dormiam em esteiras de fibras, começaram a usar roupas, dormir em redes, usar cobertores etc.

As visitas intertribais também são cada vez mais comuns, seja por motivo de festa, pajelança e até mesmo político. A roupa é freqüentemente usada como objeto de troca entre os integrantes da própria aldeia e com índios de outras tribos do Xingu.

Entre os índios, o contato íntimo é mais freqüente devido as suas características culturais.

Para se abrigar do frio noturno, os Panará acendem pequenas fogueiras e se deitam de uma maneira curiosa, todos juntos, encostados uns nos outros, de forma a se aquecer mutuamente (CAMPINAS 1973). 
Muitos tem redes e já não dormem com esteiras diretamente sobre o chão, mas ainda são muitas as famílias que estendem suas esteiras sobre enormes camas feitas de troncos, dormindo agrupados com grande proximidade.

A aldeia é composta de 158 pessoas que se distribuem em sete casas o que dá uma média de vinte e três pessoas em cada uma delas. As casas tradicionalmente pertence as mulheres que vivem com marido e filhos. Quando as filhas se casam continuam morando com a mãe e os filhos vão morar com a família da sogra. Atualmente as casas são feitas de madeira roliça e cobertas de palha à moda das casas dos seringueiros.

Um fato importante de se observar é que os índios têm o costume de se banhar várias vezes durante o dia, molhando suas roupas, que secam no próprio corpo, oferecendo ambiente ideal para proliferação do Sarcoptes scabiei.

O contato íntimo mais intenso, associado ao uso inadequado da roupa e exiguidade de sabão, foram as condições ideais para a proliferação.

Pesquisa realizada numa comunidade de índios Xavante de Pimentel Barbosa no estado do Mato Grosso em 1991 observou uma alta prevalência de escabiose (66\%), pediculose (37\%) e piodermite (18\%) que o autor relacionou à introdução do hábito de vestir-se dissociado de medidas apropriadas de higiene corporal e de limpeza correta das roupas (ALVAREZ et al., 1991).

Essa observação vem reforçar as mesmas conclusões a que chegamos entre os Panará no Parque Indígena do Xingu - Mato Grosso.

\section{AÇÃO EDUCATIVA}

Antevendo as dificuldades da comunidade em compreender e aceitar o trabalho a ser desenvolvido, foi planejada uma ação educativa em duas fases, visando a se conseguir maior adesão, colaboração e eficácia do tratamento a ser realizado. A primeira fase foi dirigida ao agente indígena de saúde e a segunda a toda a comunidade. Essa preocupação, respondia a uma demanda teórica baseada na importância de se envolver os sujeitos da ação educativa em todo o processo, oferecendo condições para que pudessem interferir alterando a proposta inicial da equipe no que julgassem necessário e, dessa forma, dividindo com eles a responsabilidade por cada decisão. 
Essa parceria entre os dois pólos da intervenção, profissionais de saúde e os agentes indígenas de saúde foi considerada fator imprescindível para o possível êxito da missão a ser iniciada e uma contribuição ao processo de desenvolvimento da cidadania dos indígenas. Assim, o respeito ao universo sócio cultural do grupo (conhecimento, valores, praticas, crenças, significados) foi o princípio norteador das ações dos profissionais de saúde.

A solução encontrada para facilitar a comunicação foi a confecção de um álbum seriado especificamente desenvolvido para o uso naquela aldeia.

Visando sempre uma aproximação máxima com sua realidade, esse álbum seriado foi elaborado com desenhos coloridos que explicavam a doença e reproduziam cenas do cotidiano dos índios, mostrando como acontece a transmissão, quais os sinais e sintomas da doença, como deveria ser feito o tratamento e a maneira de prevenir a reinfestação, reproduzindo situações que seriam vividas ali durante o tratamento.

Na chegada à aldeia houve uma conversa dos profissionais de saúde com o agente indígena de saúde para que ele se inteirasse do trabalho e ajudasse no processo de comunicação, pois os índios não dominavam o idioma português assim como os profissionais de saúde envolvidos no tratamento não conheciam a língua Panará.

Nessa primeira conversa com o agente indígena de saúde foi utilizado o álbum seriado que se mostrou-se um bom instrumento didático.

Após essa primeira etapa com o agente indígena de saúde, iniciou-se a segunda com a utilização do álbum seriado em uma reunião com todos os integrantes no centro da aldeia coordenada pelo agente indígena de saúde que contou à tribo, na sua própria língua, a história do "kansopo" (coceira, na língua Panará) e como eliminar a doença. Essa história mostrava a importância da aplicação da medicação, do corte das unhas, da lavagem das roupas e das ações específicas visando a prevenção da doença.

Há que se destacar um costume desse grupo que se mostrou extremamente útil ao sucesso da intervenção realizada pela enfermeira, auxiliar de enfermagem e agente de saúde. Segundo esse costume um ancião, denominado "orador da aldeia", discursa todas as noites sobre os acontecimentos do dia que se encerra e sobre as atividades a serem executadas no dia seguinte.

Esse costume foi incorporado ao plano de ação dos profissionais de saúde e, assim, informações e orientações do trabalho em andamento passaram a fazer parte da fala diária desse "orador", por constituir acontecimento importante da aldeia. 


\section{TRATAMENTO EXISTENTE, PROPOSTO E ADOTADO}

Os índios vinham tratando o prurido e as lesões da pele por meio de banhos com cascas de árvores, sem bons resultados. Após um período de alívio, o prurido voltava.

É comum ver os índios saindo para a mata em busca de medicamentos.

Quando procuram a nossa medicina, geralmente já iniciaram também o tratamento com suas ervas. Mesmo após o uso da nossa medicina permanecem com seus métodos. Suas plantas medicinais são do conhecimento de grande parte dos integrantes da aldeia, diminuindo assim o risco de cair em desuso.

Alguns desses remédios indígenas tem dono. São de uso exclusivo dos pajés. Cabe a eles o ato de receitar, pegar no mato e preparar. A maioria desses remédios são utilizados em banhos, outros misturados com água e ingeridos.

O plano de ação enviado pela Unidade de Saúde e Meio Ambiente do Departamento de Medicina Preventiva da Escola Paulista de Medicina preconizava que, após o último banho coletivo da família ao final da tarde, cada pessoa deveria aplicar o medicamento benzoato benzila, aplicação esta feita fora de casa e aproveitando a última luz solar para que o medicamento secasse no corpo. A aplicação seria realizada durante três noites seguidas devendo, após sete dias de intervalo, ser repetida por mais três noites. No entanto, como vimos anteriormente, o plano de ação foi modificado para se adequar ao hábitos daquela tribo indígena.

O tratamento começou imediatamente após uma reunião com toda a comunidade no centro da aldeia e teve início com o corte das unhas das mãos e pés, seguido do banho e aplicação do benzoato de benzila, que era aplicado duas vezes ao dia sobre todo o corpo, permanecendo sobre a pele por um mínimo de quatro horas.

Após o terceiro dia de aplicação do medicamento, notou-se melhora significativa nos quadros de escabiose. Essa melhora também foi sentida por eles que diziam estar conseguindo dormir. Com uma semana de intervalo, o tratamento foi repetido.

As piodermites em crianças e adolescentes foram tratadas com penicilina $G$ benzatina e pomada de neomicina bacitracina, além de banhos com permanganato de potássio, medicamentos disponíveis na aldeia. 
Paralelamente, usava-se a loção, o sabonete e o shampoo de deltametrina. A maioria das lesões eram em couro cabeludo mas esses produtos a base de deltametrina só eram usados em situações emergenciais, devido a pequena quantidade disponível na aldeia.

Após quatro dias de tratamento, já estavam todos em bom estado podendo fazer uso do benzoato de benzila.

\section{PARTICIPAÇÃO DA COMUNIDADE, DIFICULDADES ENCONTRADAS E ADAPTAÇÕES}

A rotina finalmente estabelecida para a realização do tratamento resultou de uma série de ajustes nos quais o agente indígena de saúde e as lideranças da aldeia tiveram papel fundamental.

Segundo a visão indígena, não adiantaria fazer o tratamento que propúnhamos se não houvesse também rezas para "espantar o espírito da sarna" que, para eles, seria o causador da doença. Assim as rezas foram realizadas junto com o tratamento proposto.

Decidiu-se começar pela aplicação do medicamento em todas as crianças, enquanto o restante da comunidade observava e, em seguida, o mesmo procedimento foi repetido com os adultos.

Sendo final de tarde, três horas após a aplicação do medicamento, os índios foram tomar banho no rio antes de dormir. Esse fato causou espanto aos profissionais de saúde, pois eles tinham sido orientados a dormir com a loção no corpo.

A resposta veio de uma conversa com o agente indígena de saúde que explicou que os índios não queriam dormir com a loção no corpo por não suportar seu odor.

Também se observou que, após a aplicação do medicamento, ninguém saia para caçar pois alegavam que o cheiro do medicamento no corpo espantava os animais.

Outro problema que teve de ser contornado dizia respeito à curta permanência do medicamento na pele devido a freqüência dos banhos. Para aumentar a exposição, a loção começou a ser aplicada em todas as pessoas da aldeia, logo depois do banho matinal. Após a aplicação, permaneciam nus por um período de 4 a 5 horas, enquanto executavam suas tarefas diárias, expostos ao sol ou não, só depois, iam se banhar. No período da tarde, a operação era repetida. 
Outra dificuldade encontrada envolvia as crianças pequenas, que acabavam levando a mão aos olhos, o que provocava irritação local. Elas choravam devido ao ardor. Esse problema foi solucionado pelas próprias mães, que após a aplicação da loção, envolviam as mãos delas com embira (fibra vegetal) ou pano.

Problema semelhante acontecia com as mulheres que estavam amamentando e também tinham dificuldade em usar o benzoato de benzila porque os bebês, que ficam o tempo todo no colo para mamar, acabavam ingerindo o medicamento ou tendo a região ocular irritada. Essa situação foi resolvida com o uso da loção de deltametrina que tem odor mais agradável e não é irritante, com a vantagem de permitir uma única aplicação feita antes de dormir.

Também se observou um problema no uso do benzoato de benzila no couro cabeludo das crianças menores de quatro anos que apresentavam irritação nos olhos devido ao escorrimento do medicamento. A solução adotada foi o uso do shampoo de deltametrina.

Para se proceder à lavagem e fervura das roupas, cobertores e redes, foi necessário escavar uma vala no chão onde foram colocadas panelas de cerca de 60 litros, sustentadas por grandes toras de madeira às quais se ateava fogo.

Observe-se que todos esse procedimentos dependiam de uma mudança nos hábitos da aldeia, além de muito esforço físico. Às cinco horas da manhã, os homens saiam para pescar ou caçar e as mulheres iam à roça providenciar o alimento e a lenha a ser usada no preparo dos mesmos e na fervura das roupas.

Por volta das oito horas, as mulheres retornavam com seus cestos carregados de lenha e comida, no que eram auxiliadas pelas meninas.

A água utilizada vinha do rio, o que também exigia grande esforço para seu transporte.

A fervura das roupas, incluindo cobertores e redes, era feita separadamente, por família, começando logo pela manhã e continuando por todo o dia.

Para auxiliar na eliminação dos parasitas enquanto as roupas ficavam de molho foi utilizado uma loção de lindano. Essa prática se limitou ao primeiro dia porque o produto manchou todas as peças. O plano de ação teve que ser mudado e as roupas passaram a ser apenas lavadas com sabão no rio, sendo em seguida fervidas e postas para secar ao sol. Por iniciativa própria, as famílias estabeleceram uma escala de trabalho visando facilitar todo esse processo. 
Antes que os profissionais de saúde deixassem a aldeia, o agente indígena de saúde foi devidamente orientado a tratar os casos novos ou remanescentes de escabiose e a solicitar ajuda via rádio amador, caso necessitasse de orientação.

Em 1996 os Panará iniciaram sua mudança para aldeia Naycepotire. Nessa época observamos casos de escabiose concentrados em uma mesma família. Os doentes foram tratados e orientados juntamente com o agente indígena de saúde.

\section{CONSIDERAÇÕES FINAIS}

Qualquer trabalho realizado em área indígena deve ter como diretriz o respeito e a valorização das diferentes práticas do sistema tradicional de saúde que compõem suas organizações sociais e culturais, devendo envolver a participação da comunidade.

O trabalho do agente indígena de saúde e de educação deve ser valorizado pelos diversos profissionais que colaboram com a saúde indígena pois eles representam o elo de ligação entre o nosso sistema de saúde e a população indígena..

Os índios sofrem influências da nossa cultura mudando seus hábitos rapidamente. Como até então não possuíam registros, grande parte de seus conhecimentos acaba se perdendo. É necessário retomar com essas comunidades seus hábitos positivos de higiene, formas tradicionais de prevenção e cuidado com as doenças.

É importante que os diversos profissionais de saúde que passam pela aldeia (mesmo que por curtos períodos), assim como os agentes indígenas de saúde e outros profissionais que muitas vezes colaboram com a saúde, façam uso rotineiro do "livro ata", registrando todas as intercorrências, casos atendidos, constando nome, sexo, idade, diagnóstico, tratamento e evolução da doença. Só com a continuidade desses registros podemos estudar a morbidade e ter controle sobre medicamentos usados, melhorando assim a assistência à saúde da população.

As diversas entidades e organizações que trabalham com índios devem estimular relatórios e publicações sobre trabalhos executados nessas áreas pois existe uma distância muito grande entre o meio acadêmico e os profissionais de campo, o que leva ao empobrecimento da qualidade dos ações praticadas. 
CONCLUSÃO

Após a implementação das ações, tanto terapêuticas, quanto educativas, a epidemia foi controlada, resultando no desaparecimento da escabiose na aldeia.

Tal fato evidencia os bons resultados do processo de ensino e aprendizagem desenvolvido com o agente indígena de saúde e a validade das estratégias educativas escolhidas.

Há que se observar que os casos de doenças nessa aldeia tem sido sub-notificados, mas não ocorreram novas epidemias de escabiose segundo registros da Escola Paulista de Medicina e FUNASA .

O agente indígena de saúde e as lideranças da aldeia tiveram papel fundamental para o sucesso do trabalho, pois eram eles que explicavam à comunidade a importância das ações praticadas, estimulando-a a colaborar e participar ativamente do processo, assim como transmitiam as dificuldades sentidas pela comunidade aos profissionais de saúde.

Nesse sentido a colaboração do "orador" da aldeia foi decisiva, pois reforçava a importância das ações desenvolvidas durante o dia, em seu discurso à noite. De forma geral, houve participação ativa de todos os membros da aldeia.

O hábito dos índios tomarem banho com roupa e continuar com ela molhada no corpo vem diminuindo, conforme tem sido observado, mas depende de reforço permanente.

A tradição oral dos índios nos revela que eles aprendem muito por repetição, de modo que os diversos profissionais de saúde, professores, agentes de saúde e educação, que atuam em área, devem estar atentos para a escabiose, reforçando as medidas de prevenção, discutindo amplamente e de forma democrática para evitar surtos epidêmicos.

Somente com o conhecimento da vida dessa comunidade, o envolvimento das lideranças locais e a atenção às reações negativas frente a medicação utilizada, foi possível adequar a terapia e criar um clima propício à introdução de novas rotinas. Isso vem enfatizar que a importância de que um trabalho dessa natureza deve ser alicerçado nos princípios da educação em saúde que regem a participação da comunidade, sem a qual essa intervenção teria sido inviabilizada. 
Finalmente, cabe considerar que esse trabalho extrapolou os limites da terapêutica, constituindo um caso de educação e promoção em saúde com resultados concretos voltados à melhoria da qualidade de vida da aldeia.

\section{REFERÊNCIAS BIBLIOGRÁFICAS}

ALVAREZ, R.R. et al. Dermatoses entre os Xavantes da área indígena Pimentel Barbosa, Mato Grosso (Brasil). Cad. Saúde Pública, 7(4):581-4, 1991.

ARNT, R. et al. Panará: a volta dos índios gigantes. São Paulo, ISA, 1998. p. 166

BARUZZI, R. et al. Os índios Panará: a busca pela sobrevivência. In: Encontro Nacional, de Estudos Populacionais, $9^{\circ}$, Caxambu, 1994. Anais. São Paulo, Ed. Abep, 1994. p. 22543.

BLUMENTHAL, D.S. et al. A community outbreak of scabiei. Am. J. Epidemiol., 104:66772, 1976.

CAMPINAS, A. S. Relatório do plano de ação do sertanista Campinas (na área de atuação do posto de atração Peixoto de Azevedo, índios kreen-Akarore), Estado do Pará. Ed. Minter - Funai, 1973. p. 15

DAVIS, S., H. Vítimas do milagre: o desenvolvimento e os índios do Brasil. Rio de Janeiro, Zahar, 1977. p. 208

GIRALDIN, O. Cayapó e Panará: luta e sobrevivência de um povo. Campinas, 1994. [Tese de Mestrado- Departamento de Filosofia e Ciências Humanas da Universidade Estadual de Campinas]

GULATI, P.V., et al. Scabies in a semiurban area of India na epidemiologica study. Int. J. dermatol., 16:594-8, 1977.

HELLAS, R. H. The social organisation of the Panará, a Ge tribe of central Brazil. Oxford, 1979. [Doctoral Dissertation, St. Catherine's College, Oxford University]

[ISA] INSTITUTO SÓCIO AMBIENTAL. Povos indígenas do Brasil 1991/1995. In: O caminho de volta: a saga dos gigantes Panará São Paulo, 1996. p. 601-14

LIEBGOTT, R.A. A lei que cria o subsistema de atenção à saúde indígena. [on line]. Brasília, 1999. Disponível em < http:// www.cimi.org.br [2000, nov, 01] 
MARCOPITO, L.F. Amarga renúncia à terra de origem. Rev. Atualid. Indigena, 3(19), 1979.

MENDES, J.P.V. Educação, saúde e liberdade: tríade para o desenvolvimento. Rev. Bras. Saúde Esc., 1(1):4-12, 1990.

[MS] MINISTÉRIO DA SAÚDE; [FNS]. Fundação Nacional de Saúde; [CSI] Coordenação da Saúde do Índio. Relatório final sobre a formação de agentes indígenas de saúde. Brasilia,1996.

ÑIGUEZ CARBONELL J.C.; et al. Sarna infantil: una entidad diferente. Am.Esp. Pediatr., 28:67-72, 1988.

ORKIN, M. Resurgence of scabies. JAMA 217: 593-7, 1971.

PASSARO , C.M. Pesquisa do Sarcoptes scabiei no hiponíquio de pacientes com escabiose clássica. São Paulo, 1991. [Tese de mestrado - Departamento de Dermatologia da Escola Paulista de Medicina]

PESSÔA, S.B. Parasitologia médica. $9^{\circ}$ ed. Rio de Janeiro, Guanabara-Koogan, 1974. p. 740-743.

RICKEY, H.K; et al. Scabies diagnosis and management. Hosp. pract 15: 124. A-Z; 1986.

SAMPAIO, S. de A.P. Dermatologia básica. São Paulo, Artes Médicas, 1974. p.160.

SCHWARTZMAN, S. The Panará of the Xingu National Park: the transformation of a society, Chicago Illinois, 1988. [Dissertation - Faculty of the Division of the Social Sciences. Department of Anthropology]

SILVA, D.; et al. Escabiose: relato de uma epidemia. An. Bras. Dermatol., 60(3):135-6, 1985.

SUÁREZ DE LA TORRE, R. Consideraciones generales sobre la escabiasis. Rev. Med. IMSS (México), 20(6):681-2,1982. 


\title{
AGRADECIMENTOS
}

\author{
Comunidade indígena Panará \\ Universidade Federal de São Paulo - UNIFESP \\ Faculdade de Saúde Pública - USP \\ Departamento de Saúde da FUNAI \\ Instituto Sócio Ambiental - ISA \\ Fundação Nacional de Saúde - FUNASA
}

\section{INVESTIGATION AND CONTROL OF SCABIES EPIDEMICS: AN EDUCATIVE EXPERIENCE IN AN INDIGENE VILLAGE}

\begin{abstract}
SUMMARY: This work reports on an epidemic of scabies in a village of the tribe Panará, located in Xingu, Mato Grosso, Brazil. The educational strategies utilized and the difficulties found to obtain the adhesion of the comunity for the therapeutics actions, essentials to the control of the epidemic are discussed. These strategies, based on an conceptual framework for education in health rooted on the respect for the knowledge, values and necessities of the group, considered the participation of the comunity an essential element for the the adjustment of the initial plan. The actions and combined decisions of health profissionals, local leaderships and target population, made possible the investigation and the control of the epidemic.
\end{abstract}

KEY WORDS: Brazilians indians, epidemic, scabies, health community agent, health promotion, health education 